\title{
The Brazilian Way to Consume açaí: Do guaraná Extract and Sugar Concentrations Influence on Acceptance?
}

\author{
Gabriela Montenegro $^{1}$, Karen S. Pereira ${ }^{1} \&$ Lauro $_{\text {Melo }}{ }^{1}$ \\ ${ }^{1}$ Department of Biochemical Engineering, School of Chemistry, Federal University of Rio de Janeiro, Rio de \\ Janeiro, Brazil \\ Correspondence: Lauro Melo, Department of Biochemical Engineering, School of Chemistry, Federal University \\ of Rio de Janeiro, Rio de Janeiro, Brazil. Tel: 55-2125-627-579. E-mail: lauro@eq.ufrj.br
}

Received: August 1, 2013 Accepted: December 3, 2013 Online Published: December 6, 2013

doi:10.5539/jfr.v3n1p39 URL: http://dx.doi.org/10.5539/jfr.v3n1p39

\begin{abstract}
Açai is a palm widely distributed in the Amazon estuary floodplains. The edible pulp of açaí fruits is commonly macerated with water to produce a thick, purple beverage of creamy texture, oily appearance, and characteristic flavor. Depending on the Brazilian region, the açaí based-product is prepared adding sugar and guaraná extract, but their ideal proportions have never been determined in order to optimize consumers' sensory acceptance. This research investigated these concentrations using response surface methodology (RSM) based on a five-level, two variable central composite rotatable design (CCRD). Dependent variable was consumer acceptance (flavor, texture and overall liking) and results were analyzed by multivariate regressions. Analyses of Variance (ANOVAs) showed significant models - F-test values (29.3 for flavor, for texture 37.8 and 30.4 for overall liking) higher than the critical value of 4.35 (d.f. $=3 ; \mathrm{p}<0.05 ; \mathrm{R}^{2}$ of 0.926 for flavor, 0.942 for texture and 0.929 for overall liking). Acceptance models are presented (significant parameters). Results showed that guaraná extract has a stronger influence (negative) on acceptance compared to sugar (positive), both not on optimal conditions yet. Therefore, more studies are needed in order to optimize açaí acceptance.
\end{abstract}

Keywords: açaí, guaraná, sugar, sensory evaluation, RSM

\section{Introduction}

Açaí (Euterpe oleracea Mart.) is a tropical palm tree that occurs naturally in the Amazon region. Its spherical grape-sized fruits are green when young and ripen usually to a dark purple (Strudwick \& Sobel, 1988). An important reloading point for açaí is the city of Belém in Pará State, Brazil, where fruits can be collected throughout the year. In the production region, açaí is integrated in the daily dietary habits of the native people and is normally used in main meals for lunch or dinner. In modern Brazilian society, it has gained interest as a nutritionally valuable wellness product (Strudwick \& Sobel, 1988).

The edible pulp of açaí fruits is commonly macerated with water to produce a thick, purple beverage of creamy texture, oily appearance, and characteristic flavor (Pacheco-Palencia et al., 2007). Depending on the Brazilian region (namely, Rio de Janeiro and São Paulo), the açaí based-product is prepared adding sugar and guaraná extract (another plant - Paullinia cupana var. sorbilis) (Klein et al., 2012).

Guaraná (Paullinia cupana, Sapindaceae) is a Brazilian native plant, with seeds being the only part suitable for human consumption (Saldana et al., 2002). Guaraná, a low-growing bush-type plant, is the richest vegetable source of caffeine (Mehr et al., 1996; Weckerle et al., 2003). The seeds also contain theophylline, theobromine, xanthine derivatives and tannins. They also contain saponins, starch, fats, choline and pigments (Bruneton, 1999; Edwards et al., 2005; Henman, 1982; Seidemann, 1998).

The sugar concentration in açaí cannot be estimated following the pattern of other fruits because the ideal sweetness preferred by consumers varies depending on the fruit used. Thus, for each fruit juice or other product, the ideal sweetness should be determined (Cadena \& Bolini, 2011). In the açaí case, the concentration of guaraná extract also influences in the final sweetness, making this estimate even harder.

In Rio de Janeiro, açaí is consumed on the beaches and has become very popular among fans of the "culture of health" and among people who regularly attend gyms. In the US, consumers knew açaí was healthy, nutritive, and rich in vitamins, minerals and antioxidants (Menezes et al., 2011). 
Açaí is also sold directly to the consumer, where demand for the product, once considered exotic, is growing and gaining popularity among locals and tourists. It is estimated that 500 tons / month of açaí are consumed in Rio de Janeiro, 150 tons / month in São Paulo and 200 tons / month in other states (Homma, 2008).

Response surface methodology (RSM) is an important tool in process and product improvement (Altan et al., 2008). RSM consists of a group of mathematical and statistical procedures that can be used to study relationships between one or more responses (dependent variables) and a number of factors (independent variables) (Diniz \& Martin, 1996). In the last decade, RSM has been successfully used to adjust formulations (Abdullah \& Cheng, 2001; Castro et al., 2004; Murphy et al., 2004; Chu \& Resurreccion, 2005; Granato et al., 2010; Melo et al., 2013) and process conditions (Chávez-Jáuregui et al., 2000; Mendes et al., 2001; Loh et al., 2005; Fernández et al., 2006; Kumar et al., 2009; Rehrah et al., 2009), reducing the number of trials and providing multiple regression approach to achieve optimization (Gan et al., 2007). However, to the best of our knowledge, there are no studies using response surface methodology to explore the best concentration of guaraná and sugar in the commercial açaí. In addition, the consumption of this açaí based-product (simply named as 'açaí') has traditionally been made in small/medium fruit juice houses and the proportion between guaraná extract and sugar on açaí has never been determined in order to optimize consumers' sensory acceptance.

Therefore, the objective of the current exploratory study was to evaluate the influence of guaraná extract and sugar used in the Brazilian açaí based-product on its sensory acceptance. No standard guaraná extract and sugar proportion was clearly seen during interviews to specialized places asking about their concentrations. This study has the potential to obtain the product with the most possible sensory appealing.

\section{Material and Methods}

\subsection{Materials}

Samples were prepared in a blender with açaí, different concentrations of unsweetened guaraná extract, sugar, water and ice.

\subsection{Sample Preparation}

Samples were prepared in a laboratory following the preliminary sensory tests made to determine the açaí concentration to be used.

\subsubsection{Ideal açaí Concentration}

Initially, the ideal concentration of açaí to be used was determined using an acceptance test with 82 açaí consumers, recruited at the Federal University of Rio de Janeiro (UFRJ).

The samples were prepared with $13.2 \%$ of unsweetened guaraná extract (amount that was reported in specialized juice houses) and five concentrations of açaí, based on the values provided for the açaí producer, in order to determine the ideal level of açaí in the final product.

The subjects were served with $20 \mathrm{~g}$ of each açaí sample, with different concentrations, and requested to evaluate the açaí flavor using the just-about-right scale (Meilgaard et al., 2010).

The samples were evaluated in individual booths in the Sensory Analysis Laboratory at UFRJ. Sample presentation was monadic in plastic cups coded with three-digit numbers, using a balanced complete block design (Walkeling \& MacFie, 1995). After testing, the ideal concentration of açaí was determined in $13 \%$.

\subsection{Response Surface Methodology}

Response surface methodology (RSM) was based on a five-level $(-\alpha,-1,0,1$, and $\alpha$ ), two variable central composite rotatable design (CCRD). The independent variables were guaraná extract $\left(\mathrm{X}_{1}\right)$ and sugar $\left(\mathrm{X}_{2}\right)$ concentrations and the dependent variable was consumer acceptance (relating to texture, flavor and overall liking). The actual concentrations and values encoded for guaraná and sugar are shown in Table 1. In order to determine the concentrations of guaraná and sugar thirteen juice houses were interviewed and they informed the concentrations used in their products. Reported concentrations ranged from $4.76 \mathrm{ml} /$ (100 grams of açaí) to $50 \mathrm{ml} /$ (100 grams of açaí). 
Table 1. Central composite rotatable design with coded levels and actual variable values

\begin{tabular}{ccccc}
\hline \multirow{2}{*}{ Samples } & \multicolumn{2}{c}{ Coded levels } & \multicolumn{2}{c}{ Actual levels } \\
\cline { 2 - 5 } & X1 & X2 & Guaraná (\%) & Sugar (\%) \\
\hline 1 & -1 & -1 & 10.82 & 6.49 \\
2 & 1 & -1 & 39.18 & 6.49 \\
3 & -1 & 1 & 10.82 & 23.51 \\
4 & 1 & 1 & 39.18 & 23.51 \\
5 & -1.41 & 0 & 5 & 15 \\
6 & 1.41 & 0 & 45 & 15 \\
7 & 0 & -1.41 & 25 & 3 \\
8 & 0 & 1.41 & 25 & 27 \\
9 & 0 & 0 & 25 & 15 \\
10 & 0 & 0 & 25 & 15 \\
11 & 0 & 0 & 25 & 15 \\
\hline
\end{tabular}

The results were analyzed by a multiple linear regression method which describes the effects of variables in firstand second-order polynomial models (STATISTICA 7.0 - StatSoft, Inc.). Experimental data were fitted to the selected models and regression coefficients obtained.

\subsection{Consumer Testing}

Participants ("açaí" consumers - at least once a month, recruited amongst faculty staff and students) evaluated açaí samples to determine liking of texture, flavor, buying intention and overall liking. A total of 84 consumers, male and female, varying from 18 to 53 years-old, have participated in this study.

Consumer affective testing was carried out using a 9-point hedonic scale, from 'dislike extremely' to 'like extremely' (Meilgaard et al., 2010).

Samples $(20 \mathrm{~g})$ coded with three-digit numbers were presented monadically in a balanced block design (MacFie et al., 1989) to 84 consumers in plastic coups. Sensory tests were carried out in the university laboratory. Taste-free water and crackers were provided for palate cleansing. Consumers' decisions were based solely on the sensory characteristics of the samples, since product information and formulation were not provided.

\section{Results and Discussion}

Dependent variables flavor, texture and overall liking were analyzed by multivariate regressions and significances of the models were tested (Burkert et al., 2005) by Analysis of Variance (ANOVA), providing F-test values (29.3 for flavor, for texture 37.8 and 30.4 for overall liking) higher than the critical value of 4.35 (d.f. $=3 ; \mathrm{p}<0.05 ; \mathrm{R}^{2}$ of 0.926 for flavor, 0.942 for texture and 0.929 for overall liking). Thus, it was possible to present statistically valid models (Equations below) for these sensory acceptance attributes (only statistically significant and marginally significant $-\mathrm{p}<0.1-$ model terms are shown):

$$
\begin{gathered}
\text { Flavor }=2.82-1.02 \mathrm{X}_{1}+0.407 \mathrm{X}_{1}^{2}+0.369 \mathrm{X}_{2} \\
\text { p-values: }<0.01(\text { Intercept }) ;<0.05\left(\mathrm{X}_{1}\right) ;<0.1\left(\mathrm{X}_{1}^{2}\right) ;<0.1\left(\mathrm{X}_{2}\right) \\
\text { Texture }=4.19-0.419 \mathrm{X}_{1}+0.461 \mathrm{X}_{1}^{2}+0.178 \mathrm{X}_{2} \\
\text { p-values: }<0.000(\text { Intercept }) ;<0.01\left(\mathrm{X}_{1}\right) ;<0.01\left(\mathrm{X}_{1}^{2}\right) ;<0.01\left(\mathrm{X}_{2}\right) \\
\text { Overall liking }=3.10-0.823 \mathrm{X}_{1}+0.510 \mathrm{X}_{1}^{2}+0.270 \mathrm{X}_{2} \\
\text { p-values: }<0.01(\text { Intercept }) ;<0.05\left(\mathrm{X}_{1}\right) ;<0.05\left(\mathrm{X}_{1}^{2}\right) ;<0.1\left(\mathrm{X}_{2}\right)
\end{gathered}
$$

(Where $\mathrm{X}_{1}$ is percentage of guaraná and $\mathrm{X}_{2}$ is percentage of sugar)

Equations 1, 2 and 3 showed that the guaraná concentration decreased $(\mathrm{p}<0.05)$ flavor, texture and overall liking in the linear model terms. Sugar concentration increased $(p<0.05)$ flavor, texture and overall liking in the linear model terms. However, guaraná concentration increased $(p<0.05)$ flavor, texture and overall liking in the 
quadratic model terms while sugar caused no influence $(p>0.05)$ in these terms. A better understanding of the influence of the sensory descriptive attributes on the açaí samples with different concentrations of guaraná and sugar would be achieved applying a descriptive technique. Having both results (acceptance from consumers and descriptive data from a trained panel) it will be possible to correlate both sets of data, using a multivariate technique such as partial least square regression or multiple factor analysis, in order to understand acceptance patterns based on sensory descriptive profile.

Close to the used concentration range, there was a tendency of guaraná to reach a maximum and then to decrease the sensory acceptance (due to the observed quadratic effect) while sugar did not seem to exhibit this effect near the studied concentration range.

In order to confirm the influence of guaraná and sugar concentrations on açaí sensory acceptance, contour diagrams were also generated for flavor, texture and overall liking (Figures 1, 2 and 3), showing higher liking values on lower guaraná concentrations regions and the stronger influence of guaraná as opposed to sugar. In the figures, the values of $\mathrm{X}$ and $\mathrm{Y}$ axes were used the encoded values.

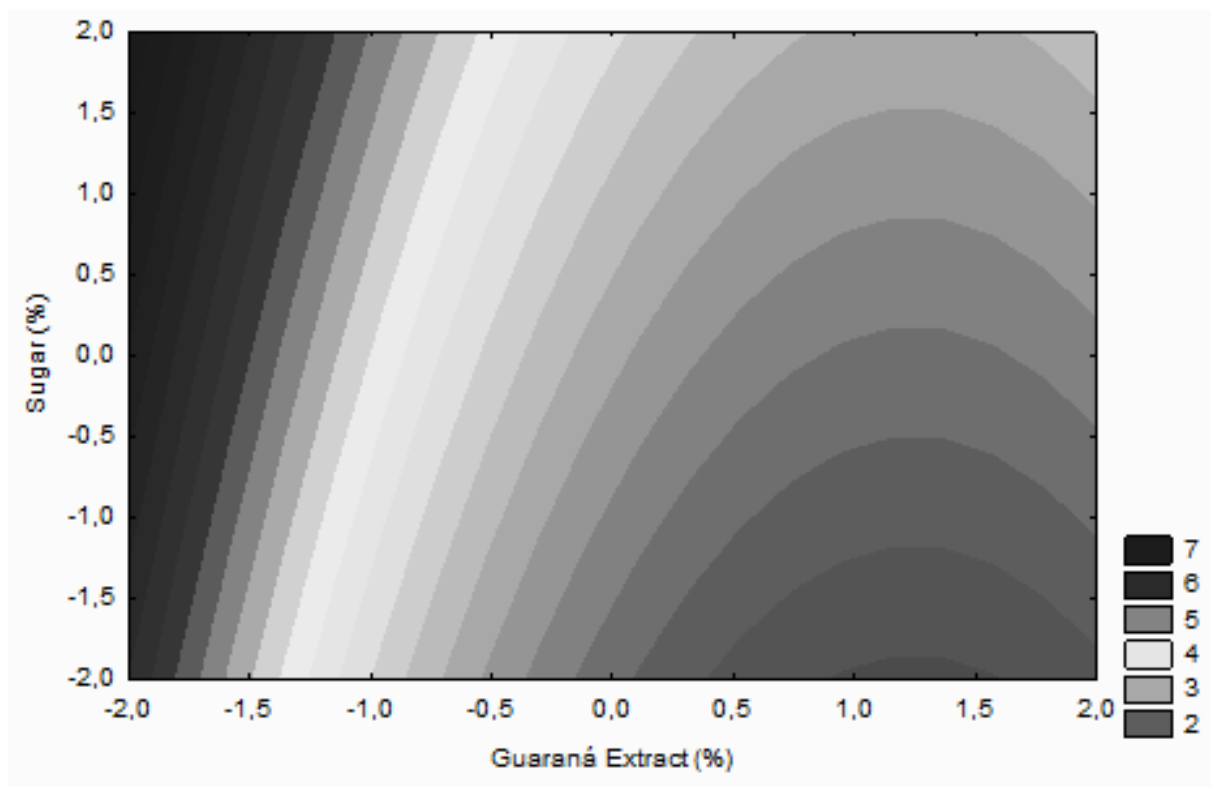

Figure 1. Contour diagram for flavor

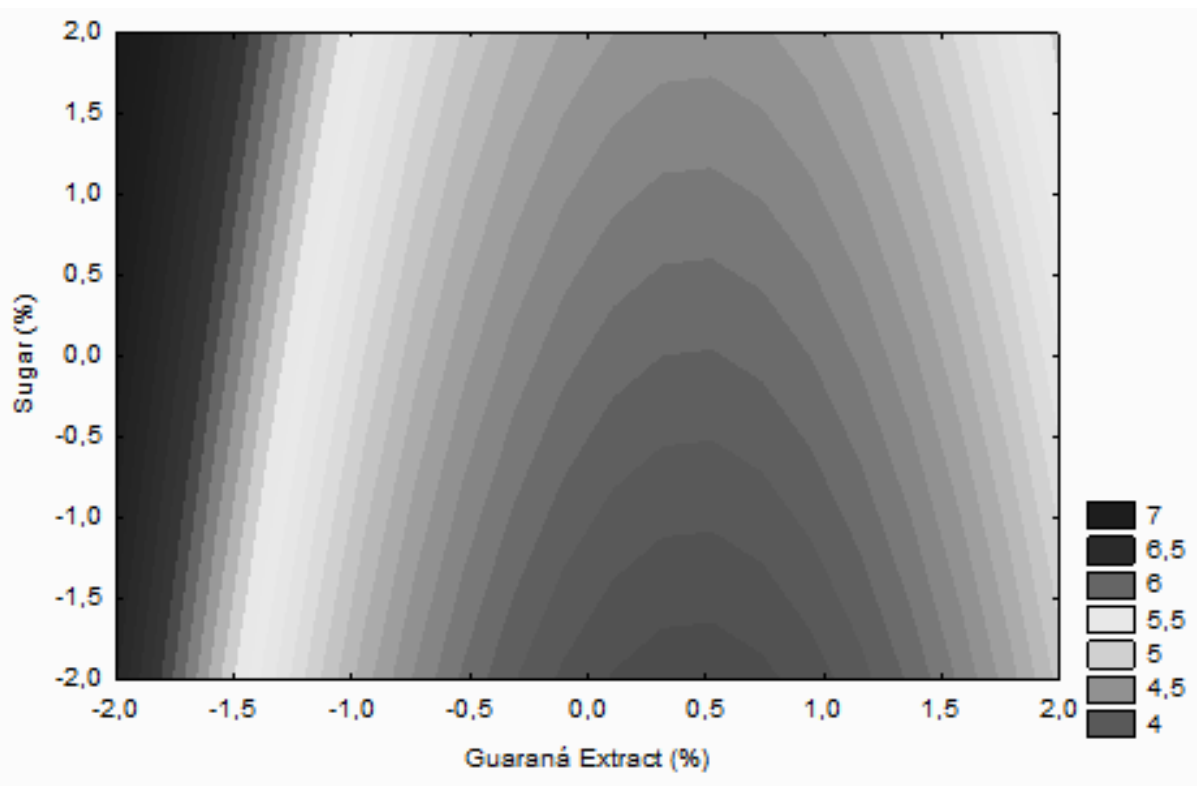

Figure 2. Contour diagram for texture 


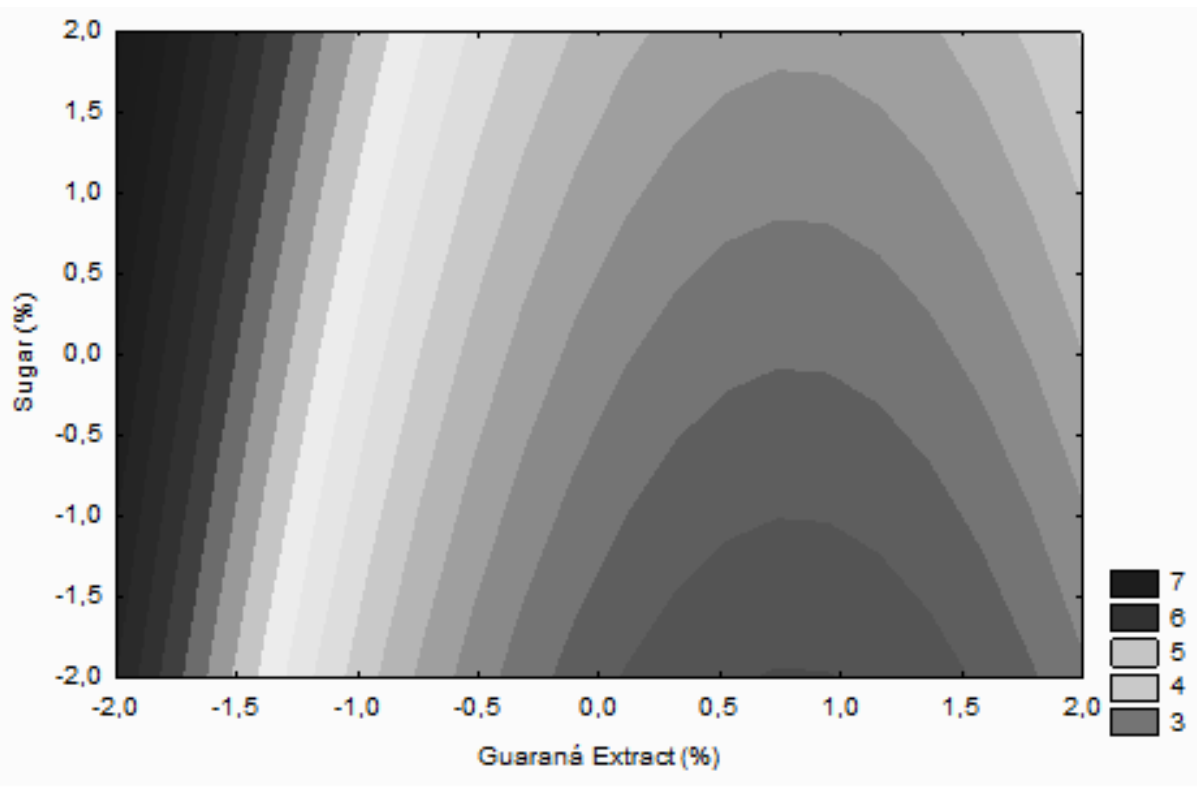

Figure 3. Contour diagram for overall liking

The major chemical constituents in guaraná seeds are the methylxanthine derivatives: caffeine, theophylline and theobromine (Heard et al., 2006). During the studies, many people reported feeling a strong bitterness in the samples of açaí. That bitterness is explained by the presence of caffeine, present in guaraná, which has a characteristic bitter taste.

Bitterness is generally viewed as an undesirable attribute of foods and beverages (Mattes, 1994), and consumers reported that "taste" is the single most important factor in food and beverage selection (Glanz et al., 1998). Therefore, this bitterness (and its negative effect on sensory acceptance) could be reduced by increasing the concentration of sugar in the samples, which would increase samples' acceptance, as our results have shown. However, other studies have been associating sugar-sweetened beverages with development of metabolic syndrome and type 2 diabetes (Malik et al., 2010), as well as with a greater magnitude of weight gain (Schulze et al., 2004). Therefore, it would be important to correlate the sugar concentration to behavioral characteristic of each consumer in future studies. Another possibility to mask bitterness reducing the need of higher amounts of sugar is adding other products to the açaí based-product, such as banana.

A study evaluated North American consumers' acceptance, intention to purchase and attitudes towards different açaí-based products available in the US and showed a promising market, indicating this product's consumption mainly by women and health conscious consumers (Menezes et al., 2011). This shows a growth trend of açaí to other countries besides Brazil.

However, Brazil still must address some points regarding its açaí production. For instance, the high national and international demand of the açaí fruit has caused disagreements in local supply, as previously the production of açaí in the Amazon region was almost exclusively to care domestic demand. This situation has become more difficult with the above mentioned increasing external demand, not followed by the same increasing in supply. There has been a change of attitude on the part of the extractive producers, which chose to seek new production alternatives in order to address the future expectations of this market (Turini, 2011). Sensory and consumer studies on açaí characteristics and acceptance have the potential to increase açaí internal and external demands and Brazilian producers must be prepared for that.

\section{Conclusions}

Results showed that concentrations of added guaraná extract and sugar affect consumer acceptance of Brazilian açaí in different ways. Sugar concentration increased flavor, texture and overall liking in the linear model terms. And guaraná extract concentration increased flavor, texture and overall liking in the quadratic model terms while sugar caused no influence in these terms. Results suggested that guaraná extract characteristic bitterness (and its negative effect on sensory acceptance) could be reduced by increasing the concentration of sugar in the samples. 
For the optimization of açaí sensory acceptance, future research would be needed, since the optimal concentrations were not found in this study.

\section{References}

Abdullah, A., \& Cheng, T. C. (2001). Optimization of reduced calorie tropical mixed fruits jam. Food Quality and Preference, 12(1), 63-68. http://dx.doi.org/10.1016/S0950-3293(00)00030-6

Altan, A., McCarthy, K. L., \& Maskan, M. (2008). Extrusion cooking of barley flour and process parameter optimization by using response surface methodology. Journal of the Science of Food and Agriculture, 88(9), 1648-1659. http://dx.doi.org/10.1002/jsfa.3262

Burkert, J. F. D. M., Maldonado, R. R., Filho, F. M., \& Rodrigues, M. I. (2005). Comparison of lipase production by Geotrichum candidum in stirring and airlift fermenters. Journal of Chemical Technology \& Biotechnology, 80(1), 61-67. http://dx.doi.org/10.1002/jctb.1157

Cadena, R. S., \& Bolini, H. M. A. (2012). Ideal and relative sweetness of high intensity sweeteners in mango nectar. International Journal of Food Science and Technology, 47, 991-996. http://dx.doi.org/10.1111/j.1365-2621.2011.02932.x

Castro, I. A., Tirapegui, J., Silva, R. S. S. F., \& Cutrim, A. J. S. (2004). Sensory evaluation of a milk formulation supplemented with $\mathrm{n} 3$ polyunsaturated fatty acids and soluble fibres. Food Chemistry, 85(4), 503-512. http://dx.doi.org/10.1016/S0308-8146(02)00456-9

Chávez-Jáuregui, R. N., Silva, M. E. M. P., \& Areas, J. A. G. (2000). Extrusion cooking process for amaranth (Amaranthus caudatus L.). Journal of Food Science, 65(6), 1009-1015. http://dx.doi.org/10.1111/j.1365-2621.2000.tb09408.x

Chu, C. A., \& Resurreccion, A. V. A. (2005). Sensory profiling and characterization of chocolate peanut spread using response surface methodology. Journal of Sensory Studies, 20(3), 243-274. http://dx.doi.org/10.1111/j.1745-459X.2005.00023.x

Diniz, F. M., \& Martin, A. M. (1996). Use of response surface methodology to describe the combined effects of $\mathrm{pH}$, temperature and $\mathrm{E} / \mathrm{S}$ ratio on the hydrolysis of dogfish (Squalus acanthias) muscle. International Journal of Food Science and Technology, 31(5), 419-426. http://dx.doi.org/10.1046/j.1365-2621.1996.00351.x

Fernández, C., Alvarez, M. D., \& Canet, W. (2006). The effect of low-temperature blanching on the quality of fresh and frozen/thawed mashed potatoes. International Journal of Food Science and Technology, 41(5), 577-595. http://dx.doi.org/10.1111/j.1365-2621.2005.01119.x

Glanz, K., Brasil, M., Maibach, E., Goldberg, J., \& Snyder, D. (1998). Why Americans eat what they do: Taste, nutrition, cost, convenience, and weight control concerns as influences on food consumption. J Am Diet Assoc. Journal of the American Dietetic Association, 1118-1126. http://dx.doi.org/10.1016/S0002-8223(98)00260-0

Gan, H. E., Karin, R., Muhammad, S. K. S., Bakar, J. A., Hashim, D. M., \& Rahman, R. A. (2007). Optimization of the basic formulation of a traditional baked cassava cake using response surface methodology. Lwt-Food Science and Technology, 40(4), 611-618. http://dx.doi.org/10.1016/j.lwt.2006.05.005

Granato, D., De Castro, I. A., Ellendersen, L. S. N., \& Masson, M. L. (2010). Physical Stability Assessment and Sensory Optimization of a Dairy-Free Emulsion Using Response Surface Methodology. Journal of Food Science, 75(3), S149-S155. http://dx.doi.org/10.1111/j.1750-3841.2010.01514.x

Heard, C. M., Johnson, S., Moss, G., \& Thomas, C. P. (2006). In vitro transdermal delivery of caffeine, theobromine, theophylline and catechin from extract of Guarana, Paullinia Cupana. International Journal of Pharmaceutics, 317(1), 26-31. http://dx.doi.org/10.1016/j.ijpharm.2006.02.042

Homma, A. K. O., Embrapa, Production System of Acaí, Market and Marketing, EMBRAPA. Retrieved from http://sistemasdeproducao.cnptia.embrapa.br/FontesHTML/Acai/SistemaProducaoAcai_2ed/paginas/merca do.htm

Kumar, Y. S., Prakasam, R. S., \& Reddy, O. V. S. (2009). Optimisation of fermentation conditions for mango (Mangifera indica L.) wine production by employing response surface methodology. International Journal of Food Science \& Technology, 44(11), 2320-2327. http://dx.doi.org/10.1111/j.1365-2621.2009.02076.x

Loh, S. K., Man, Y. B. C., Tan, C. P., Ozman, A., \& Hamid, N. S. A. (2005). Process optimisation of encapsulated pandan (Pandanus amaryllifolius) powder using spray-drying method. Journal of the Science 
of Food and Agriculture, 85(12), 1999-2004. http://dx.doi.org/10.1002/jsfa.2169

Macfie, H. J., Bratchell, N., Greenhoff, K., \& Vallis, L. V. (1989). Designs to balance the effect of order of presentation and first-order carry-over effects in hall tests. Journal of Sensory Studies, 4(2), 129-148. http://dx.doi.org/10.1111/j.1745-459X.1989.tb00463.x

Malik, V. S., Popkin, B. M., Bray, G. A., Despres, J. P., Willett, W. C., \& Hu, F. B. (2010). Sugar-Sweetened Beverages and Risk of Metabolic Syndrome and Type 2 Diabetes. Diabetes Care, 33(11), 2477-2483. http://dx.doi.org/10.2337/dc10-1079

Mattes, R. D. (1994). Influences on acceptance of bitter foods and beverages. Physiology \& Behavior, 56(6), 1229-1236. http://dx.doi.org/10.1016/0031-9384(94)90370-0

Meilgaard, M., Civille, G. V., \& Carr B. T. (2010). Sensory Evaluation Techniques (4 ed.). CRC Press.

Melo, L., Cardoso, J. M. P., Battochio, J. R., \& Bolini, H. M. A. (2013). Using Response Surface Methodology and High-Intensity Sweeteners' Positive Synergy to Optimize Peach Nectar Acceptability. Food and Nutrition Sciences, 4, 503-509. http://dx.doi.org/10.4236/fns.2013.45064

Mendes, L. C., Menezes, H. C., \& Silva, M. A. A. P. (2001). Optimization of the roasting of robusta coffee (C-canephora conillon) using acceptability tests and RSM, Food Quality and Preference, 12(2), 153-162. http://dx.doi.org/10.1016/S0950-3293(00)00042-2

Menezes, E., Deliza, R., Chan, H. L., \& Gguinard J. (2011). Preferences and attitudes towards açaí-based products among North American consumers. Food Research International, 44(7), 1997-2008. http://dx.doi.org/10.1016/j.foodres.2011.02.048

Murphy, S. C., Gilroy, D., Kerry, J. F., Buckley, D. J., \& Kerry, J. P. (2004). Evaluation of surimi, fat and water content in a low/no added pork sausage formulation using response surface methodology. Meat Science, 66(3), 689-701. http://dx.doi.org/10.1016/j.meatsci.2003.07.001

Rehrah, D., Ahmedna, M., Goktepe, I., \& Yu, J. (2009). Extrusion parameters and consumer acceptability of a peanut-based meat analogue. International Journal of Food Science and Technology, 44(10), 2075-2084. http://dx.doi.org/10.1111/j.1365-2621.2009.02035.x

Schulze, M. B., Manson, J. E., Ludwig, D. S., Colditz, G. A., Stampfer, M. J., Willett, W. C., \& Hu, F. B. (2004). Sugar-sweetened beverages, weight gain, and incidence of type 2 diabetes in young and middle-aged women. JAMA: The Journal of the American Medical Association, 292(8), 927-934. http://dx.doi.org/10.1001/jama.292.8.927

Turimi, E. (2011). Açaí (fruto)- Período 01 a 30/01/2011. Conjuntura Mensal (CONAB). Retrieved from http://www.conab.gov.br/OlalaCMS/uploads/arquivos/11_02_01_08_11_54_conjunturaacaijaneiro2011.pdf

\section{Copyrights}

Copyright for this article is retained by the author(s), with first publication rights granted to the journal.

This is an open-access article distributed under the terms and conditions of the Creative Commons Attribution license (http://creativecommons.org/licenses/by/3.0/). 